\title{
Enablers, Difficulties and Features to Implement E-Learning Technology in Conventional Higher Education: Case Study and Prototype Implication
}

\author{
Yimer Amedie Muhie, Cheru Haile Tesfay, Biniyam Wondie Tamirat \\ Department of Information Technology, Assosa University, Assosa, Ethiopia \\ Email:ymr4u.asu@gmail.com
}

How to cite this paper: Muhie, Y.A., Tesfay, C.H. and Tamirat, B.W. (2020) Enablers, Difficulties and Features to Implement E-Learning Technology in Conventional Higher Education: Case Study and Prototype Implication. Journal of Software Engineering and Applications, 13, 219-244. https://doi.org/10.4236/jsea.2020.1310015

Received: August 31, 2020

Accepted: October 11, 2020

Published: October 14, 2020

Copyright $\odot 2020$ by author(s) and Scientific Research Publishing Inc. This work is licensed under the Creative Commons Attribution International License (CC BY 4.0).

http://creativecommons.org/licenses/by/4.0/

(c) (i) Open Access

\begin{abstract}
Supporting higher education with modern technologies like E-Learning is very important for one country to improve quality of education, to meet student's expectations and to continue teaching-learning and training when face to face education is impossible. However, it is in its preliminary stage in developing countries like Ethiopia. This study examined the enabling factors, difficulties and opportunities of E-Learning implementation in Assosa University (ASU), Ethiopia. Its purpose is to find the enabling factors, difficulties and opportunities of E-Learning implementation in ASU and developing prototype of E-Learning system to show its practicality and to identify approaches of students' and lecturers towards E-Learning. The study employed questionnaires, observation and interview to gather the required information. A sample of 309 students and 64 Lecturers randomly selected from 7 colleges and two schools as well as ICT workers and other concerned bodies in the university. Also prototyping as a methodology was used to implement and test the proposed system for proof of concept. This study investigating the possibility of implementing E-Learning in ASU and important enablers, difficulties and opportunities is identified. Also the E-Learning platform of the university is developed and introduced for students and lecturers to show its practicality. Most students and lecturers showed good motivation in E-Learning implementation and they assumed that it is useful for the university. The result shows that although there are difficulties to implement E-Learning in ASU, the possibility of fully implementing E-Learning in the University is relatively high with mixed method. With this, the approaches of students and lecturers are positively viewed and the opportunities are very noticeable in the University. So, conventional higher education can practi-
\end{abstract}


cally implement E-Learning with mixed approach to use as supportive tool for educational improvements and to reduce physical presence.

\section{Keywords}

E-Learning, Enablers of E-Learning, Difficulties of E-Learning, E-Learning Implementation, Prototyping

\section{Introduction}

\subsection{Background}

Today, advancement of technologies changes almost all our day to day activities all over the world. This is because Information and Communication Technology (ICT) is considerably changing the entire way of human life and their activities. Educational system is the most relatively benefited systems from the technologies, which gradually changes the techniques of teaching and learning process and the key to improving education [1]. Information and Communication Technology (ICT) is developing very rapidly. It is a diverse set of technological tools and resources used to communicate, create, disseminate, store, and manage individual or organizational information. E-learning is one part of ICT which is very developing technology. It is the delivery of a learning or education program by the use of a computer or electronic device like mobile phone in some way to provide educational or learning materials [2] through the web. It is comparatively new developing technology used in many universities and other institutions. It concentrates on utilizing Knowledge of teachers in a way that academic courses can be delivered anywhere and anytime. E-learning is a modern way of learning, which includes electronic media in the field of education and has significant role in education and training especially in higher education [3]. The application of teaching and learning methods that promotes deep and active learning and creativity in students is the emphasis of the present educational system of Ethiopia. With this, linking universities with industries by using improved technology together with business focused approach are very necessary. Now a day, there are many problem solving technologies which are designed to improve educational system including E-learning. With this, there is no doubt that E-learning can replace part of the traditional classroom learning in Universities.

However, Assosa University uses traditional instructional delivery system for a long time in which a classroom with lecturers gives speeches to students and the students listening and taking notes. Some fields of studies with the help of laboratory rooms for certain limited time as a tool to deliver practical lessons. In this platform a critical learning component is the communication between the lecturers and students which can limit creativity and broader concept development. It affects quality of education and student's ability to be skilful and crea- 
tive by pushing them to take this traditional way as the only learning mechanism. Yet, Assosa University as higher education must produce skilful, competitive and creative individuals. They must educate students to be creative and thoughtful with high academic ability. To achieve this, the traditional teaching methods (lecturing and others) do not have the required effectiveness, but implementation of e-learning in teaching-learning process could be a way to realize this goal [4]. It will have different contribution in the current education system like; it will be used as knowledge management tool, interesting learning platform, creativity, resources sharing and skill development tools. However, to prevent budget overrun and failure, Universities have to be prepared to implement E-learning to benefit from it. This is because, successful implementation of E-learning requires that the University's E-learning preparedness has to be measured first [5]. Hence, this study investigated the enabling factors, challenges and features of E-learning implementation. Also student's approach to learn using E-learning and prototype implementation of the E-Learning system in ASU have been conducted. So that this study is the base line to implement fully functional E-learning system in Assosa University supporting the teaching and learning process with technology.

\subsection{Statement of the Problem}

The application of teaching and learning methods that promotes deep and active learning and creativity in students is the emphasis of the present educational system of Ethiopia. With this, linking universities with industries by using improved technology together with business focused approach is very necessary. Now a day, there are many problem solving technologies which are designed to improve educational system including E-Learning. There is no doubt that E-Learning can replace part of the traditional classroom learning in Universities. However, to prevent budget overrun and failure, Universities have to be prepared to implement E-Learning to benefit from it. Successful implementation of E-Learning requires that the University's E-learning preparedness has to be measured first [5].

In Ethiopia, some universities are exercising E-learning concepts by deploying E-learning system and by delivering some course lessons online. However, due to different reasons, traditional learning (talk and chalk) is being used with rare computer based learning in Assosa University. It affects quality of education and student's ability to be skillful and creative by pushing them to take this traditional way as the only learning mechanism. In order to overcome some challenges associated with quality of education, skillfulness, interest and creativity, inability to grasp key ideas and concepts; there is need for application of E-learning to support the current education system with technologies and to enable students to teach themselves using the system in the absence of lecturers. This study investigated the enabling factors, difficulties and features to implement E-learning in Assosa University. 


\subsection{Research Questions}

This study was intended to answer the following questions.

- What are the challenges and enabling factors to implement E-learning?

- Will it possible to implement E-learning in conventional higher education?

- What approaches students and lecturers have towards E-Learning with respect to ASU?

\subsection{Objectives}

\subsubsection{General Objective}

The main goal of the study was to explore the enabling factors, difficulties and features of E-Learning implementation in conventional higher education and prototype implication in Assosa University.

\subsubsection{Specific Objectives}

Specific objective of this study were:

- To investigate the challenges facing conventional higher education to implement E-Learning.

- To identify enabling factors in E-learning implementation.

- To conduct the survey of potential uses of E-learning.

- To develop and evaluate prototype of E-learning system to show its practicality.

\subsection{Concept of E-Learning}

The idea of E-learning is definitely not new especially in the outside world which was started around 1960s by linking computer terminals with classrooms where the students could listen to recorded lectures of a particular course. After that, the growth of internet, multimedia and networking gives birth to E-learning [3]. Learning Management System (LMS) was the first real E-learning invention which offered off-the-shelf platforms for front-end registration and course cataloguing. During this, skill management and reporting was tracked on the back-end [6]. This enabled departments and companies to place courses online and be able to track students' progress, communicate with students effectively and provide a place for real-time discussions.

Now a day, E-learning becomes a provision of success in higher education as it enhances the quality of teaching and learning in one country [5]. Using E-learning, not only enhancing quality of teaching and learning but also increases' individual ability to use computer technology and other emerging technologies.

Hence, E-Learning refers to the use of systems of electronic education such as computer, internet, intranet, multimedia disks, electronic magazines, virtual newscasts, and etc. whose purposes are to reduce time and expenses and achieve better, faster, and easier learning [4]. E-Learning becomes a crucial component of teaching in universities. It becomes a common style of providing educational materials in higher education by universities in every part of the world. Because 
of these changes there is an increasing need for flexible delivery of education.

E-Learning has different definitions from different perspectives and dimensions. The dimension has different attributes and meanings. Table 1 summarizes the dimensions of E-Learning (Wagner et al., 2008) with clear meaning and examples.

\subsection{E-Learning Software}

E-Learning software is the software which is used to create digital educational materials. Due to the primary purpose of e-learning tools is to author, or create, educational asset, sometimes it is called E-Learning authoring software. With this type of software, trainers and educators [7] can:

- Combine and arrange disparate media (text, video, presentations) into comprehensive, logically sequenced E-Learning assets and courses

- Add animations and customized response cues to facilitate learner engagement with E-Learning course material

- Safely store E-Learning assets for future editing and reapplication with new learning initiatives

- Publish completed E-Learning courses in a variety of compatible formats

E-learning platforms are used to create a wide variety of educational and training materials for use in many industries, both in the public and private sectors special in universities. Given this, the E-Learning software landscape includes a large selection of applications which includes in Table 2.

Table 1. The Dimensions of E-Learning.

\begin{tabular}{|c|c|c|c|}
\hline Dimension & Attribute & Meaning & Example \\
\hline \multirow[t]{2}{*}{ Synchronicity } & Asynchronous & $\begin{array}{l}\text { content delivery occurs at a different } \\
\text { time than receipt by the student }\end{array}$ & $\begin{array}{l}\text { lecture module delivered via } \\
\text { email }\end{array}$ \\
\hline & Synchronous & $\begin{array}{l}\text { content delivery occurs at the same } \\
\text { time as receipt by the student }\end{array}$ & lecture delivery via web cast \\
\hline \multirow[t]{2}{*}{ Location } & Same place & $\begin{array}{l}\text { students use an application at the same } \\
\text { physical location as other students } \\
\text { and/or the instructor }\end{array}$ & $\begin{array}{l}\text { using a GSS to solve a } \\
\text { problem in a classroom }\end{array}$ \\
\hline & Distributed & $\begin{array}{l}\text { Students use an application at various } \\
\text { physical locations, separate from other } \\
\text { students and the instructor }\end{array}$ & $\begin{array}{l}\text { using a GSS to solve a } \\
\text { problem from distributed } \\
\text { locations }\end{array}$ \\
\hline \multirow[t]{2}{*}{ Independence } & Individual & $\begin{array}{l}\text { students work independently from one } \\
\text { another to complete learning tasks }\end{array}$ & $\begin{array}{l}\text { students complete e } \\
\text { learning modules } \\
\text { autonomously }\end{array}$ \\
\hline & Collaborative & $\begin{array}{l}\text { students work collaboratively with one } \\
\text { another to complete learning tasks }\end{array}$ & $\begin{array}{l}\text { students participate in } \\
\text { discussion forums to share } \\
\text { ideas }\end{array}$ \\
\hline \multirow[t]{2}{*}{ Mode } & $\begin{array}{l}\text { Electronically } \\
\text { only }\end{array}$ & $\begin{array}{l}\text { all content is delivered via technology, } \\
\text { there is no face-to-face component }\end{array}$ & $\begin{array}{l}\text { an electronically enabled } \\
\text { distance learning course }\end{array}$ \\
\hline & Blended & $\begin{array}{l}\text { e-learning is used to supplement } \\
\text { traditional classroom learning }\end{array}$ & $\begin{array}{l}\text { in class, lectures are } \\
\text { enhanced with hands on } \\
\text { computer exercises }\end{array}$ \\
\hline
\end{tabular}


Table 2. Sample functionality of E-Learning Software.

\begin{tabular}{ll}
\hline Templates & $\begin{array}{l}\text { Provide pre-configured models for different types of e-learning } \\
\text { materials, such as lessons or quizzes. This makes it easier for users to } \\
\text { create materials, since they don't need to be designed from scratch. }\end{array}$ \\
\hline Multimedia tools & $\begin{array}{l}\text { Allow users to upload and integrate multimedia files (i.e., videos and images) } \\
\text { into e-learning resources, as well as do basic editing on these files. }\end{array}$ \\
SCORM-compliance SCORM is a set of technical standards that e-learning solutions must follow. & $\begin{array}{l}\text { Products with SCORM support help users create materials that can be } \\
\text { combined and integrated with any other SCORM-compliant materials. }\end{array}$ \\
Testing tools & $\begin{array}{l}\text { Allow users to add quizzes, tests and exams to e-learning courses, which can } \\
\text { be used to track or determine student progress. }\end{array}$ \\
Customization tools & $\begin{array}{l}\text { Help users create e-learning resources that match the look and feel of their } \\
\text { company's digital assets (such as its website). }\end{array}$ \\
Storyline editing & $\begin{array}{l}\text { E-learning courses often progress much like stories, with a linear beginning } \\
\text { and end. Storyline editing functions let authors mix, match and rearrange } \\
\text { e-learning components. }\end{array}$ \\
Interaction tools & $\begin{array}{l}\text { Let authors add elements that students will interact with during a lesson or } \\
\text { course. Interactions can include free-form text entry, picture selection or } \\
\text { simple mouse clicks. }\end{array}$
\end{tabular}

\subsection{E-Learning and Educational Improvements}

As different studies shows [4] [8] [9] [10], E-Learning enhances educational quality and skill of learners in all fields of studies and at all level.

E-Learning can offer effective instructional methods, such as practicing with associated feedback, combining collaboration activities with self-paced study, personalizing learning paths based on learners' needs and using simulation and virtual laboratories. Further, all learners receive the same quality of instruction because there is no that much dependence on a specific instructor rather they depends on the contents found in the system.

With the advancement of information technology, conventional learning has been extended to embrace the virtual learning system in higher educational system which has created opportunities for students, instructors and the society at large to access information to study and to learn in both formal and informal setting.

Web-based applications such as Learning Management Systems (LMS) enable teachers and learners to engage interactively in study materials and instructions are generally not imparted but information co-shared, assignments submitted online using "an integrated set of web-based tools for learning and course management". Learning Management System or LMS is a software application designed to facilitate virtual education and learning by helping in tasks like documentation, distribution of materials, tracking, reporting and delivery of projects [11].

Generally, it is scientifically agreed that E-learning is very important to improve academic achievement, quality of education and student's motivation [3] [4] [11] [12]. So we were glade to conduct this study to identify implementation enablers, difficulties and indispensableness as well as E-Learning implementa- 
tion issues in conventional higher educations' particularly in Assosa University, Ethiopia. This is because our study can be used as a baseline to fully implement E-learning system in the University.

\section{Methodology}

\subsection{Overview}

To investigate E-Learning implementation's enabling factors, difficulties and features in Assosa University, different methods and techniques were employed. Data collection and analysis techniques, programming and tools techniques, evaluation and testing mechanisms, comprehensive document analysis as well as prototyping as a methodology were used. Data were collected two times; firstly for identifying enablers, difficulties and opportunities of E-learning in Assosa University; secondly, for developing E-Learning prototype in Assosa University. Generally, the objectives of this study were accomplished using review of literature, data collection, data analysis and interpretation, prototyping and evaluation.

\subsection{Description of the Study Area}

The study was conducted in Assosa University, Ethiopia. Assosa University has 7 colleges and 2 schools. The two schools and the seven colleges that have been used for this research work are: school of law, school of education and behavioral science, college of engineering, college of computing and informatics, college of natural and computation science, college of social science and humanities, college of agriculture and natural resource, college of health science, college of business and economics.

\subsection{Research Design}

A research design is the technique that guides the researchers in the process of colleting, analyzing and interpreting the data. This study used qualitative research design which is focused on describing situations, phenomenon, problem or event; tends to be more in-depth and have smaller sample size [13].

During this study, starting from proposal development to final report, the methods employed are shown in the following figure. So, the first step in the study was conducting survey to identify enabling factors, difficulties and features of E-Learning implementation in Assosa University using the specified instrument for data collection described in part 2.6 of this section. After that, analyzing the collected data and implementing prototype of the system for proof of concept was the next step in the study. The final step was reviewing the whole study starting from introduction to conclusion and recommendation and delivering the final result of the study to ASU. Figure 1 shows the above described steps.

\subsection{Study Population}

The population in this study included students and lectures of Assosa University 


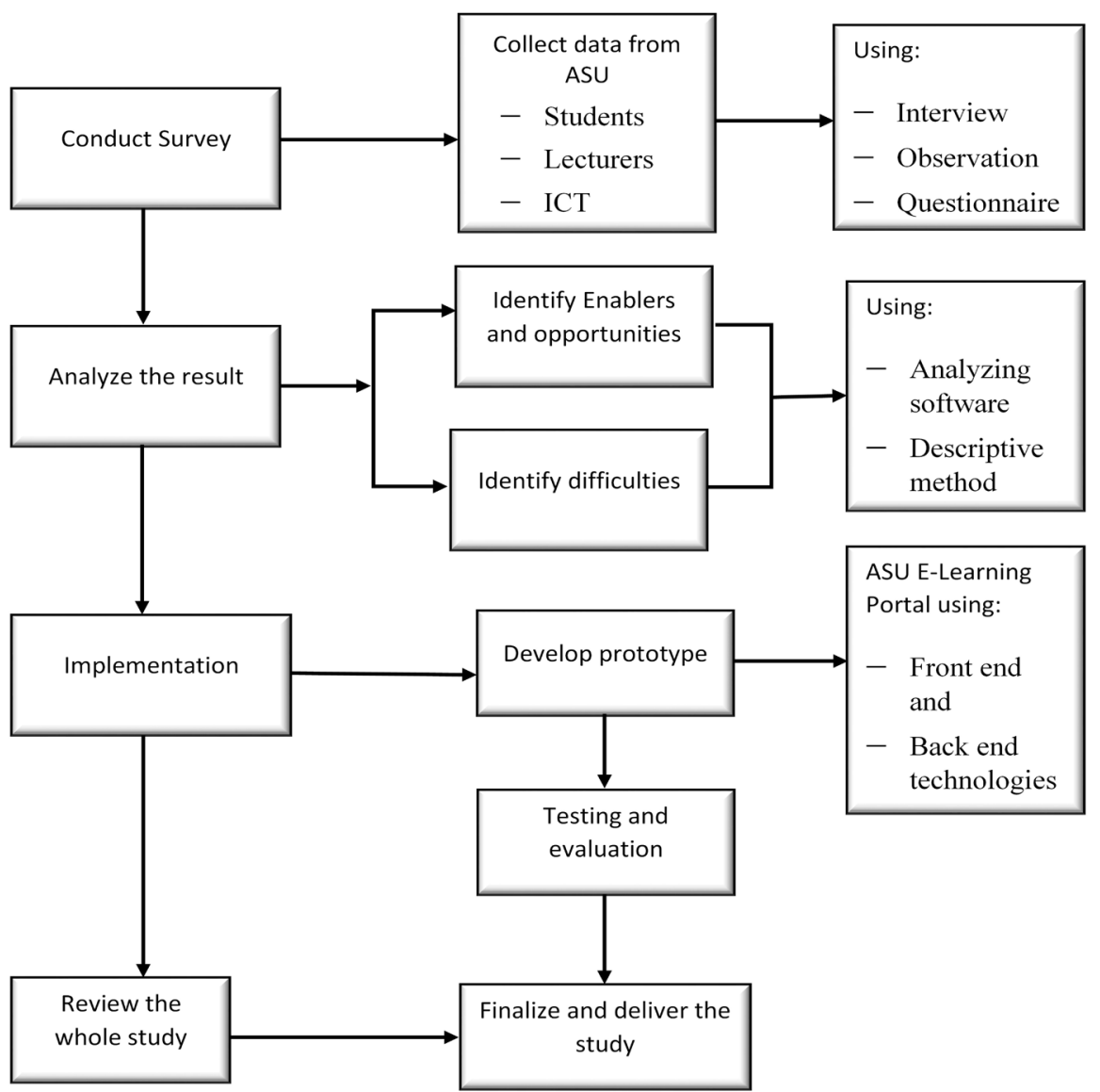

Figure 1. Research methodology.

that are from different departments and different levels of education in the university. Also ICT workers of the University were under consideration during the data collection.

\subsection{Sample of the Population}

In this study, random sampling technique was used. This is because all students and lecturers have equal chance of contribution for the study. Also purposive sampling in identification of prototype implementation area for proof of concept was used. For the purpose of determining the sample size, Cochran's formula was used with sample size of 373 .

The Cochran's formula and the sample size are shown below.

$$
n_{0}=\frac{Z^{2} p q}{e^{2}}
$$

where:

$e$ is the desired level of precision (i.e. the margin of error).

$p$ is the (estimated) proportion of the population which has the attribute in question.

$q$ is $1-p$.

$Z$ score is taken from Z-table. 
The sample size is:

The simplified formula is:

$$
n=\frac{n_{0}}{1+\frac{\left(n_{0}-1\right)}{N}}
$$

Here $n_{0}$ is Cochran's sample size recommendation, $\mathrm{N}$ is the population size, and $n$ is the new adjusted sample size. For this study, the researcher have used $95 \%$ confidence level, $5 \%$ margin of error and $50 \%$ population proportion ( $p=$ 0.5 ). $q$ is 0.5 , which is $1-p$ and $Z$ is 1.96 when confidence level is $95 \%$ from Z-table.

$$
\begin{gathered}
n_{0}=\frac{Z^{2} p q}{e^{2}} \\
n_{0}=\frac{1.96^{2} * 0.5 * 0.5}{0.05^{2}}=\frac{3.8416 * 0.25}{0.0025}=384.16 \sim 384
\end{gathered}
$$

The total population $(N)$ is 13,001 (12,487 students and 523 Lecturers and ICT workers). Using the simplified formula, the sample size is calculated below

$$
\begin{aligned}
n & =\frac{n_{0}}{1+\frac{\left(n_{0}-1\right)}{N}}=\frac{384}{1+\frac{384-1}{13001}}=\frac{384}{1+\frac{383}{13001}} \\
& =\frac{384}{1+0.0295}=\frac{384}{1.0295}=372.9966 \sim 373
\end{aligned}
$$

However, for the purpose of evaluating the prototype, additional data collection were conducted in Computing and Informatics College. At this time, only 60 students and 18 lecturers were involved. Technical system design was checked by ICT professionals, colleagues and experts.

\subsection{Instrument for Data Collection}

Interview, observation and questionnaires were used as the data collection instrument for this study. Interview was used for collecting data from college deans, department heads and ICT workers. The questionnaires were open ended and close ended and distributed to students and lecturers. The questions were aimed at eliciting relevant information concerning E-learning implementation and its enabling factors, difficulties and opportunities in Assosa University.

For the prototype implementation, there were training about its usage and other issues. After prototype is deployed and used by students, data were collected from Computing and Informatics College to evaluate its features, interface and workability.

\subsection{Data Source}

The data which is used in this study are from both primary and secondary sources. Primary data were collected through interview, observation and questionnaires and the secondary data were collected from internet resources, pub- 
lished articles and useful books. The data which is used as an input for this work is acquired from the following sources:

- Students, lecturers and ICT workers in Assosa University which includes from different departments and level of education. In this way, 7 colleges and two schools were included as a source of data. Also observation was other source of data.

- The second data source in this work is comprehensive literature review and document analysis from the internet and Assosa University libraries and newsletters.

\section{Results and Discussion}

\subsection{Overview}

In the previous sections an introduction, literature review and method of the study were provided. This section describes the result and discussion of the study in two basic parts: Enablers, Difficulties and Features in the first part and implementation overview in the second part which focused on answering the research questions and achieving the specified objectives. Figure 2 shows the results and discussion sections.

\subsection{Enablers, Difficulties and Features}

There is no conducted studies on the enablers, difficulties and prospects of implementing E-Learning in Assosa University which has investigated the possibility of implementing E-Learning in the University. This study is examined in this regard and its results are original. Typically, E-Learning implementation issues like enabling factors, difficulties and features are studied separately.

The study was conducted in Assosa University from November 2018 to June 2020. The questionnaire was distributed for 64 lecturers and ICT workers and

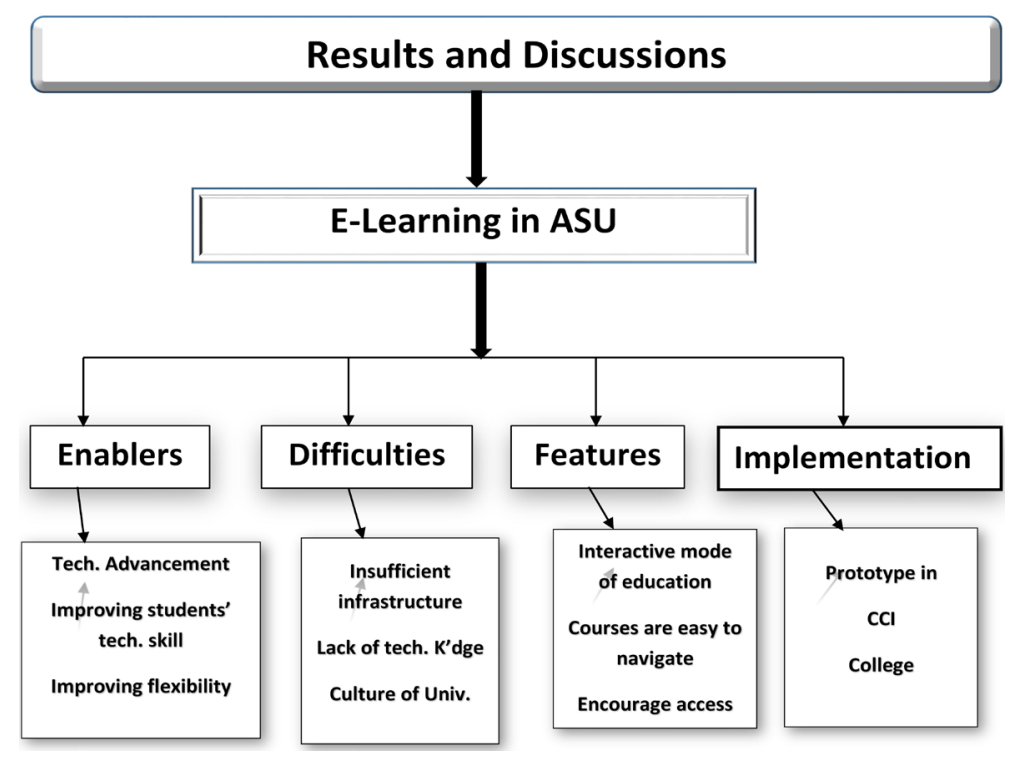

Figure 2. Overview of results and discussions. 
309 students in the University. Also for interview purpose 36 department heads, 8 college and school deans, and 12 ICT workers was participated.

A total of 340 students and lecturers from 7 colleges and one school completed the questionnaires. As the number of respondents varies from college to college, questionnaires with very few responses (answering one, two or three questions only) are not considered in this study. Something to accept in mind is that, the sample is random and included all college and school students and lecturers in equal way. During data collection, only some students and lectures in each colleges and schools who were engaged in the study decided to respond, so there is no guarantee that the sample is fully representative of all college's and school's students and lecturers in the University. Yet, it gives Assosa University a first suggestion of E-Learning implementation to support the teaching and learning process with technology. Figure 3 shows number of participants. The analysis of the data collected for this study resulted in a number of important findings, the most of which are discussed below in three basic dimensions. Firstly, the analysis of the study data showed important enabling factors that enforces implementation of E-learning in Assosa University. In this regard, the rapid development of technologies to support teaching and learning imposes any educational institutions to use educational technologies like E-Learning.

In this study, the following enabling factors are identified based on the assessment result and the latest literature concepts about this issue.

- Improving flexibility in time and space: currently, the advancement of technologies allows accessibility of learning anytime and anywhere fashion. In addition, national interests create technologically skilful and digitally connected citizens to enforce Ethiopian science and higher education to modify the current curriculum in higher education to highly consider technological environment (media).

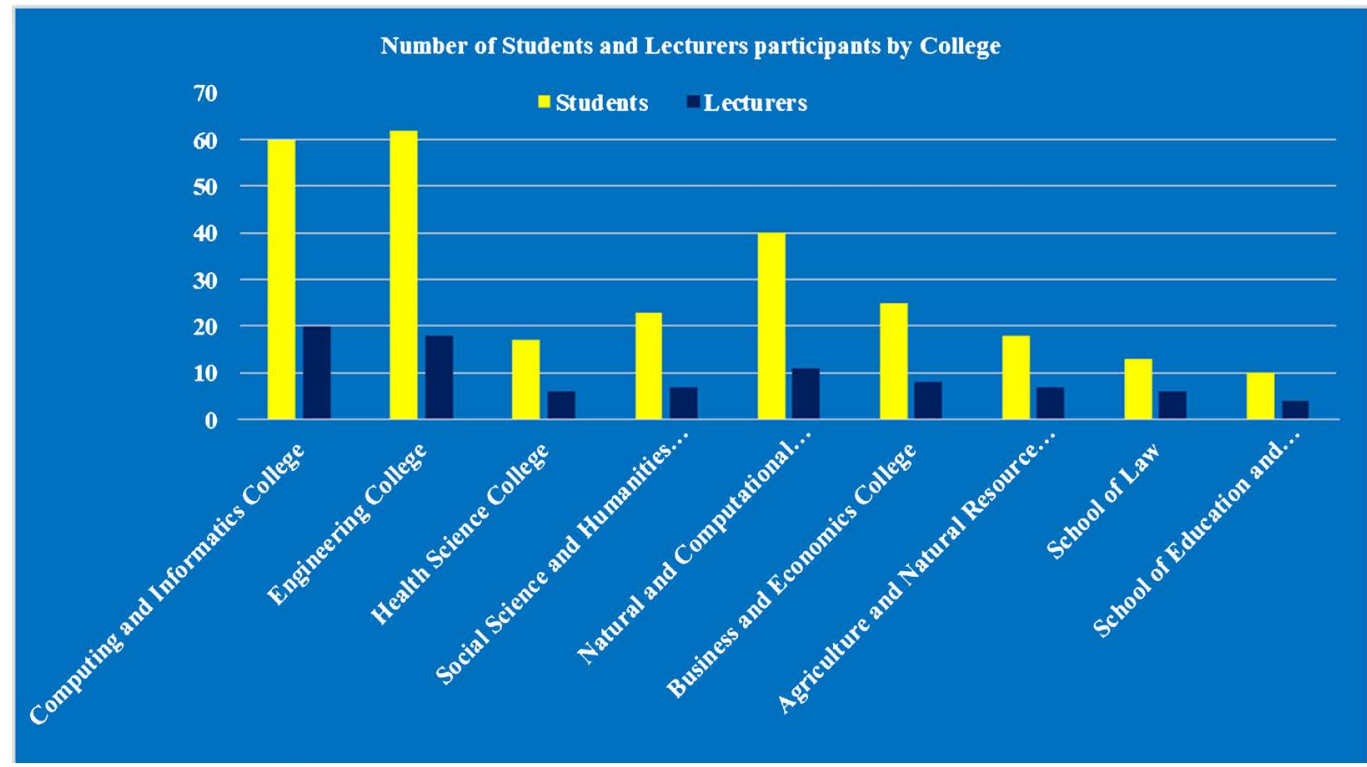

Figure 3. Number of participants from colleges and schools (students and lectures). 
- Meeting student expectations: nowadays, University students expect a lot of things when they joined higher education. With this, students want to be skilful, technologically competent and have excellent academic ability. To fulfil this requirement, Universities needs to have E-Learning.

- Enhancing teaching and learning quality: in terms of learning outcomes, there is no significant difference between traditional learning and E-Learning. However, E-Learning have great role than traditional learning to improve quality of education in Universities.

- Improving student's technology skill: in this digital time, students' needs to have technological skills for their future endeavours. With this, E-Learning has unlimited contribution to improve their technology skill.

- Enabling more active student participation: students learn best when they are actively and cooperatively engaged in their learning. So, E-Learning contribute important role to ensure active, engaged, cooperative learning.

- Distributing course materials and simplifying administrative processes More of, technological advancement, enhancing teaching and learning, meeting students' expectations, improving students' technological skills, improving cost and efficiency, distributing course materials respectively are the most enabling factors in Assosa University to implement E-Learning. These enabling factors are not exceptional only for Assosa University, but also for other Universities at large. Figure 4 shows the enabling factors of E-Learning in Assosa University.

Secondly, the analysis of the study data also showed the difficulties of E-learning

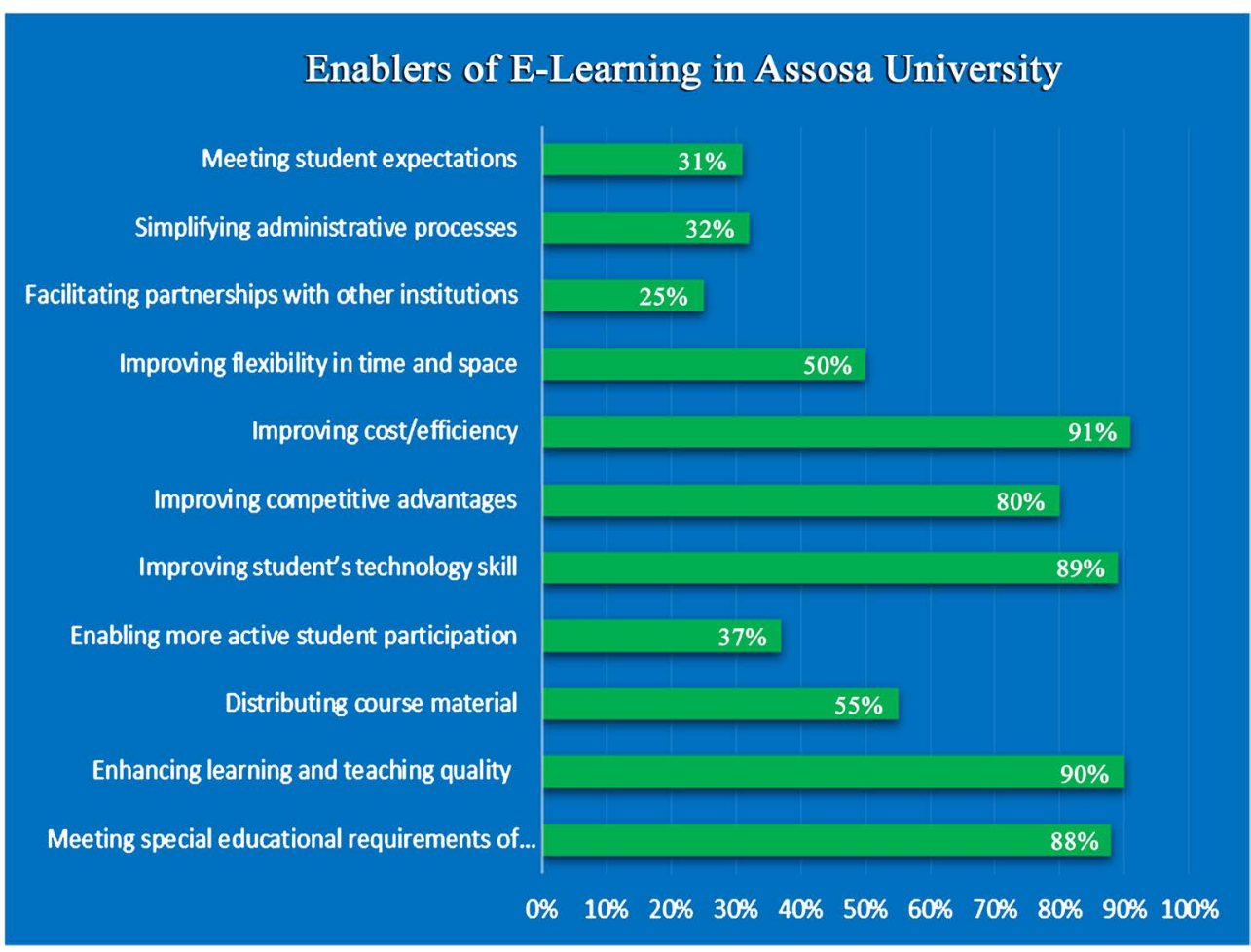

Figure 4. Enabling factors of E-Learning in Assosa University. 
implementation in Assosa University. With this corner, the analysed data and the latest literatures show that, the implementation of E-Learning over traditional learning system will provide new educational environment for the students and the lecturers. Hence, there are different difficulties that must be in consideration before the implementation. The difficulties can be individual (to students and lecturers) or organizational (to Assosa University). Figure 5 shows the difficulties of E-Learning.

The difficulties that are identified in this study are:

- Culture of the University: this can be expressed as lack of awareness about E-Learning because face to face learning is adopted and used for long period of time.

- lack of knowledge about technology: this can be expressed in terms of lack of computer skill and fear of exposure in a new environment.

- Lack of balancing time and budget of E-Learning: Lecturers need to develop and restructure their courses in a way that suits E-Learning requirements. These activities often require more time and increase workload. Additionally, there is often an expectation that lecturers will respond to their comments as soon as possible. All these activities require incentives for the lecturers. However, Assosa University have no incentive package to pay for the lecturers.

- Lack of student engagement or self-motivation: this can be expressed as lack of behavioural skills such as taking responsibility for learning and time management.

- Lack of strategies in the University: lack of proper policy and planning and supportive culture (for example, time for training, incentives, resources) this is expressed as lack of strategies to implement E-Learning in Assosa University.

- Lack of language skill: The issue of using English language is one that cannot be ignored for E-Learning to succeed the University.

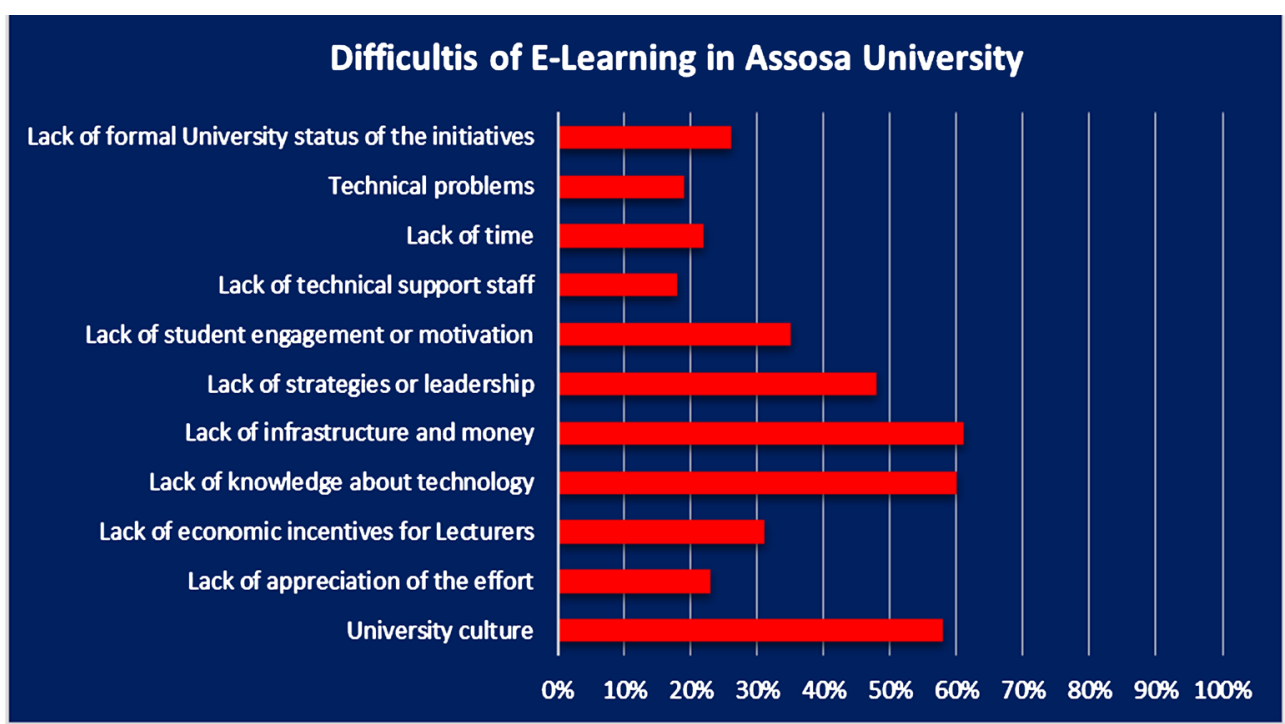

Figure 5. Difficulties of E-Learning in Assosa University. 
- Technical problems and lack of technical support staff, lack of appreciation of the effort, inequality in access to computer laboratories and internet and ethical obstacles.

At large, the five major difficulties to E-Learning in Assosa University are: insufficient computer and other infrastructures like lack of source of electric power in all area of the University, lack of knowledge about technology that is lack of computer skill and fear of exposure in a new environment, culture of the University, Lack of strategies and lack of student engagement or motivation. As different studies by different initiations, Universities, countries and individuals shows [14]-[20], these difficulties are common to all E-Learning beginner Universities as well as E-Learning experienced Universities together with pedagogical difficulties across the world.

Thirdly, the college and school participants from Assosa University have an impartial view of the University preparedness to implement E-Learning. In addition, most of the students and academic staffs as well as ICT workers of the University relatively has encouraging approach regarding to E-Learning in general. However, as the collected data shows, most of the students in the University have little understanding about E-Learning. On the other hand they want to have E-Learning system in the University. And they assumed that, it will be very important to overcome the problems of teaching learning process in Assosa University as well as to improve the quality of education in the University.

This is because E-Learning provides a number of benefits for the learners like:

- Offers an interactive mode of education

- Courses are presented in separate modules

- Learning is reinforced through clear learning objectives for each module

- Courses are easy to navigate

- Helps in developing learner's skills

- Encourages access to more related electronic course material

- Students may have the opportunity to mix what they learn with practical work

As Figure 6 shows, most of computing and informatics college students, Engineering college students, natural and computational science college students and health science college students are aware of E-Learning by different means. In addition, they are interested with E-Learning and their approach towards E-Learning is positively viewed. These amounts show how the E-Learning system is required by students in the University. Again the result of the study showed that, E-Learning implementation in Assosa University is needed by all disciplines in the University. However, School of law students in the University shows relatively very limited interest and fragile approach towards E-Learning implementation.

Generally, the analysis of the collected data, the current situation of Assosa University and the country plus the present advancement of educational technologies indicated the possibility of implementation of E-Learning system in the 
University. So, this study suggests the implementation of E-Learning in the University with blended learning concept until the top management, students and lecturers fully approached to E-Learning.

In view of that, the proposed framework of E-Learning implementation in Assosa University is demonstrated as follows which allows the implementation of traditional classroom based learning and Electronic learning in a mixed way as shown in Figure 7.

Basically, the main idea of E-Learning implementation in this context is to support the present teaching and learning process with technology and to create awareness and motive of students', lecturers' and top managers about E-Learning in the University. In addition, creating the culture of using E-Learning in the University which is easy, interactive and attractive and something to know how

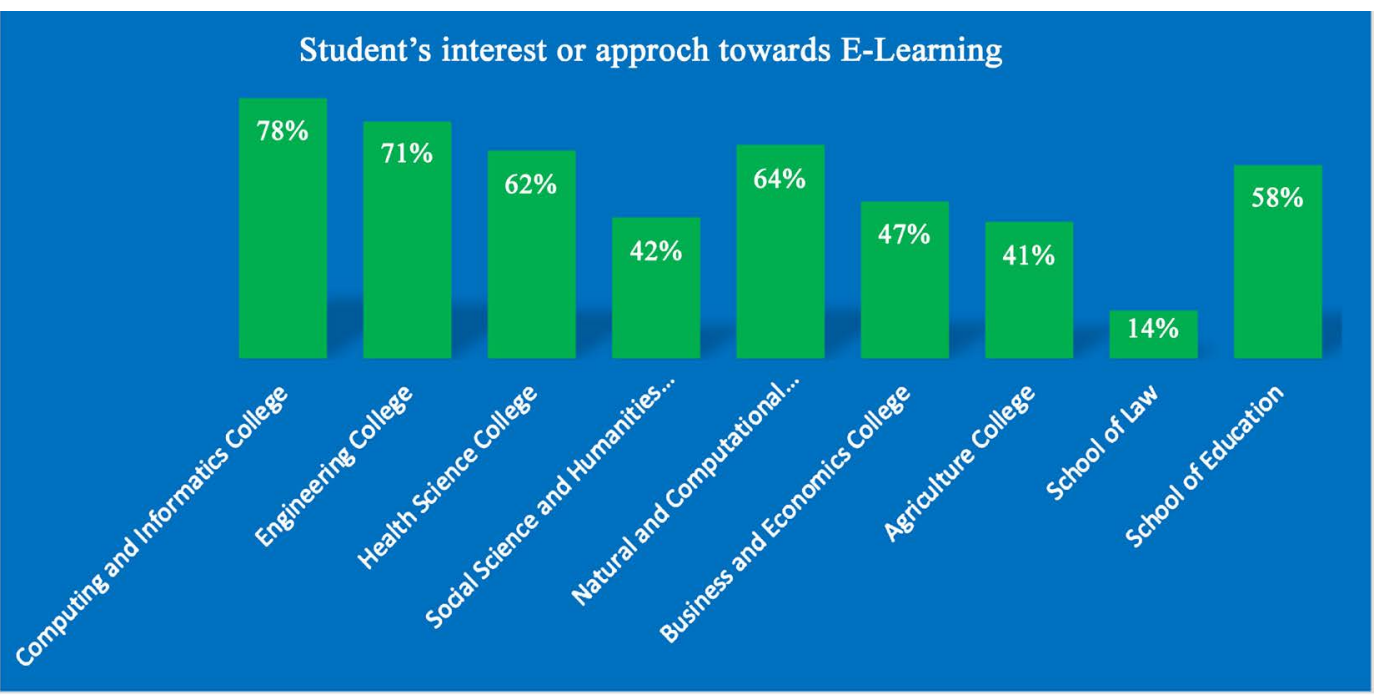

Figure 6. Students' interest and awareness towards E-Learning.

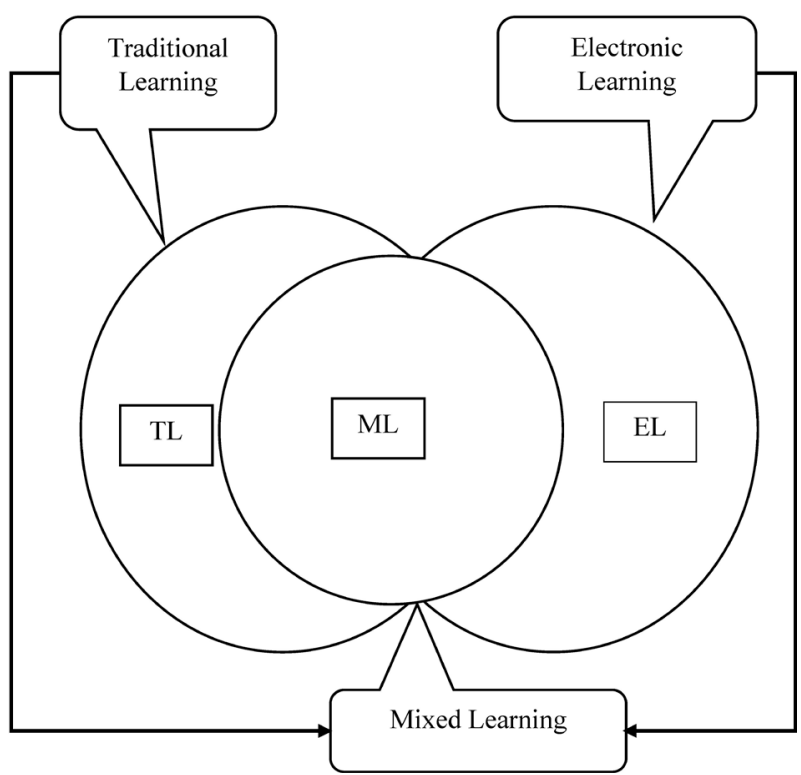

Figure 7. The framework of E-Learning in Assosa University. 
to do with it. Here, some of the tasks in teaching and learning process of Assosa University will be performed by web based learning platform or E-Learning system. For example, distribution of course materials, delivering tutorials, conducting part of continuous assessments (like giving and receiving assignments and quizzes), and active student participations using electronic discussion features with their lecturers or classmates, studying online or offline by downloading to their devices, improving student's technological skills, meeting student expectations, facilitating partnerships with industries and other organizations and creating flexibility in teaching and learning in general. These are just the first stage of activities performed by E-Learning.

\subsection{Implementation Overview}

This part is subjected to different portions of the implementation of E-Learning system. First, the design of the proposed E-Learning system discusses high level view of the system and other architectural issues. Second, business model of the system analyses current learning and teaching process in Assosa University. Third, data model of the system supports the functional requirements and defines services that the system should provide to the students and lecturers. Fourth, prototype of the system describes the sample implemented interfaces and functions of the proposed E-Learning system. Finally, evaluation of the prototype is described.

\subsubsection{Design of E-Learning System in ASU}

As shown in Figure 8, the lectures, students and administrator will have access to the learning environment or ASU Web portal using their devices like computers, laptops or mobile phones and others.

\subsubsection{Business Model}

This part describes the present process and activities of teaching and learning in Computing and Informatics College and other Colleges in Assosa University.

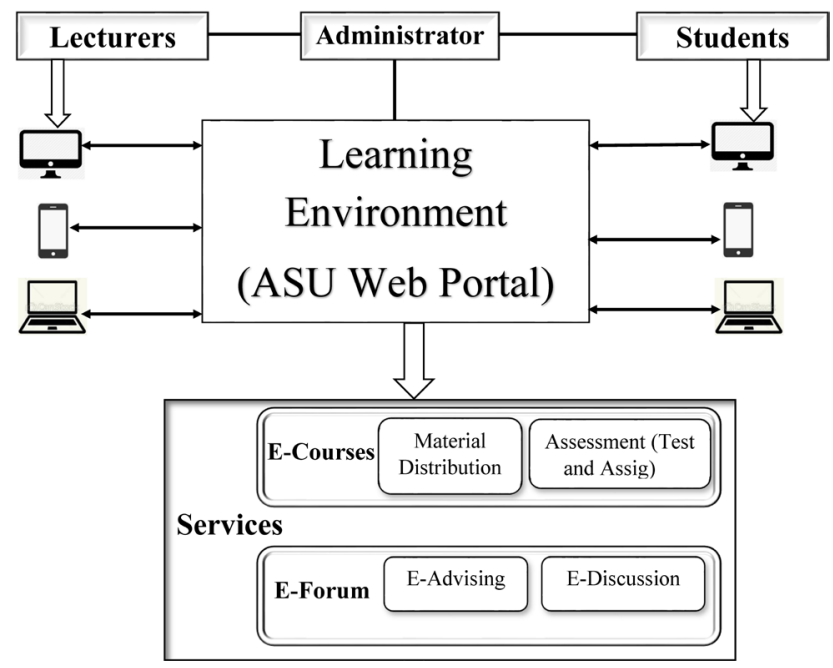

Figure 8. High level view of the proposed system. 
As shown in Figure 9 below, the process is performed in actual teaching and learning process, it is conducted to transfer knowledge and skill to students. The participants that involved in this activity are lecturer and students. This current teaching and learning process demonstrates the structure of work in teaching and learning activity in the University.

The core functions of teaching and learning processes exists in class room. In the class room the activities accomplished are: lecture delivering course, printed course materials, projects, quizzes and assessments and students attend lecturing, receive materials, projects and assignments and take quizzes and final examination. If the lecturer and students have class schedule, they will go to class room and teaching and learning will continue by transferring knowledge from lecturer to students in face to face way of teaching and learning process. If the class ended, the lecturer will go to his office and the students will go to library or other places and they will do their own activities in that place. It will be repeated until the course is completed and the students take final examination.

\subsubsection{Data Model}

The necessary data model is designed by using UML which are Use Case diagram, Activity diagram, and Sequence diagram. Use case diagram shows the overall activity, the actors and their roles that involved in developed E-Learning Portal at ASU teaching and learning process. Activity diagram is a diagram to

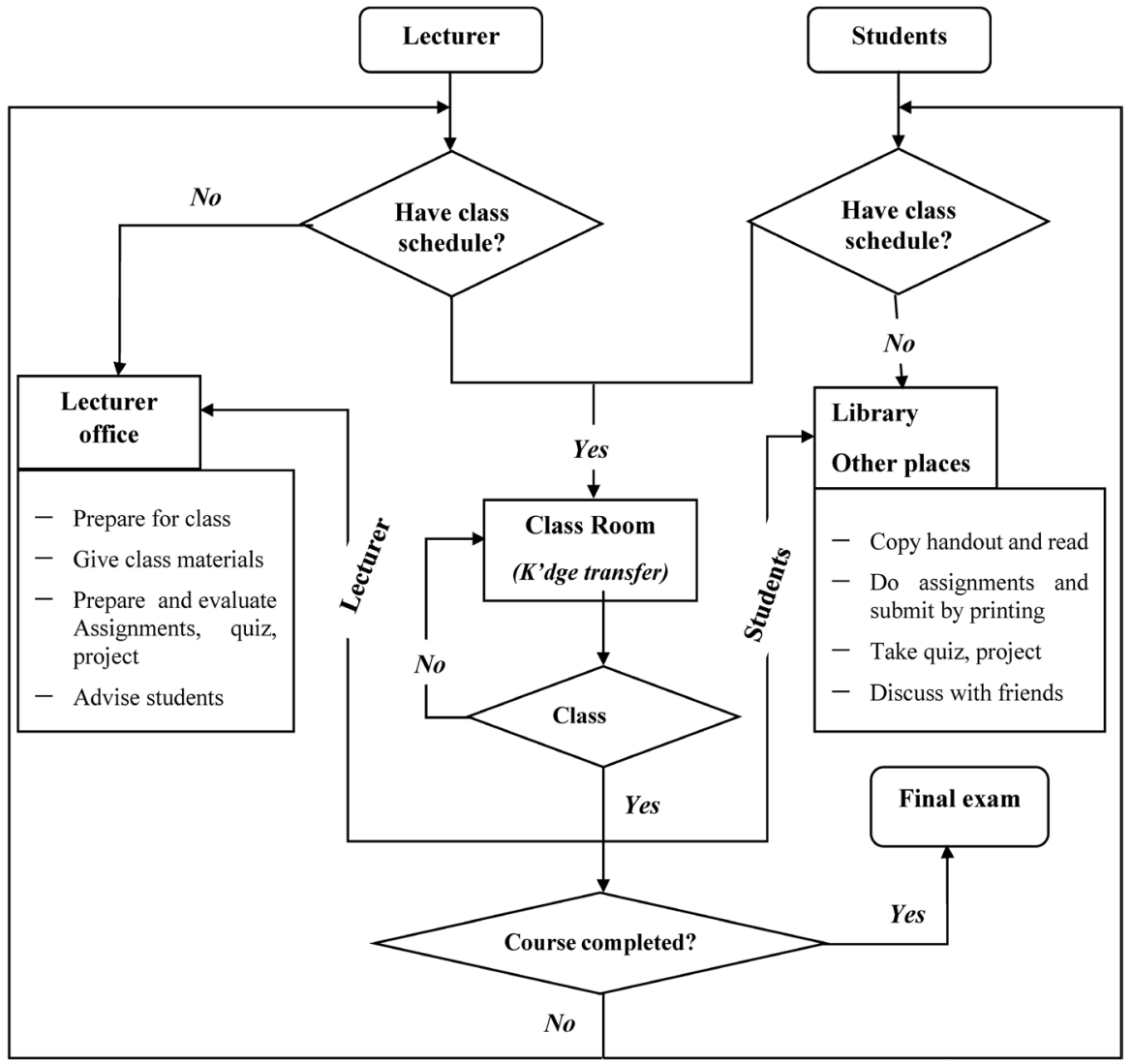

Figure 9. Current workflow/teaching-learning process in ASU. 
represent the workflows and steps of an entire system. Sequence diagram describe the way of the developed system for each actors carried out in the access pages. Figure 10 shows sample use case, Figure 11 shows sample activity diagram and Figure 12 shows sample sequence diagram respectively.

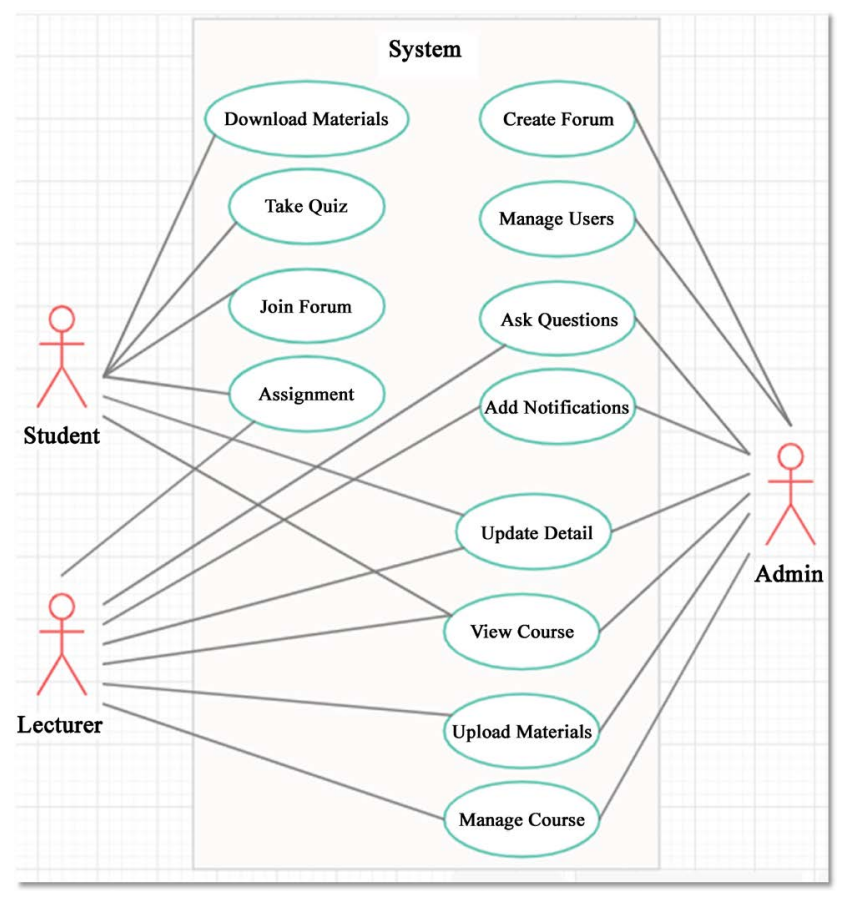

Figure 10. Use case of the proposed system.

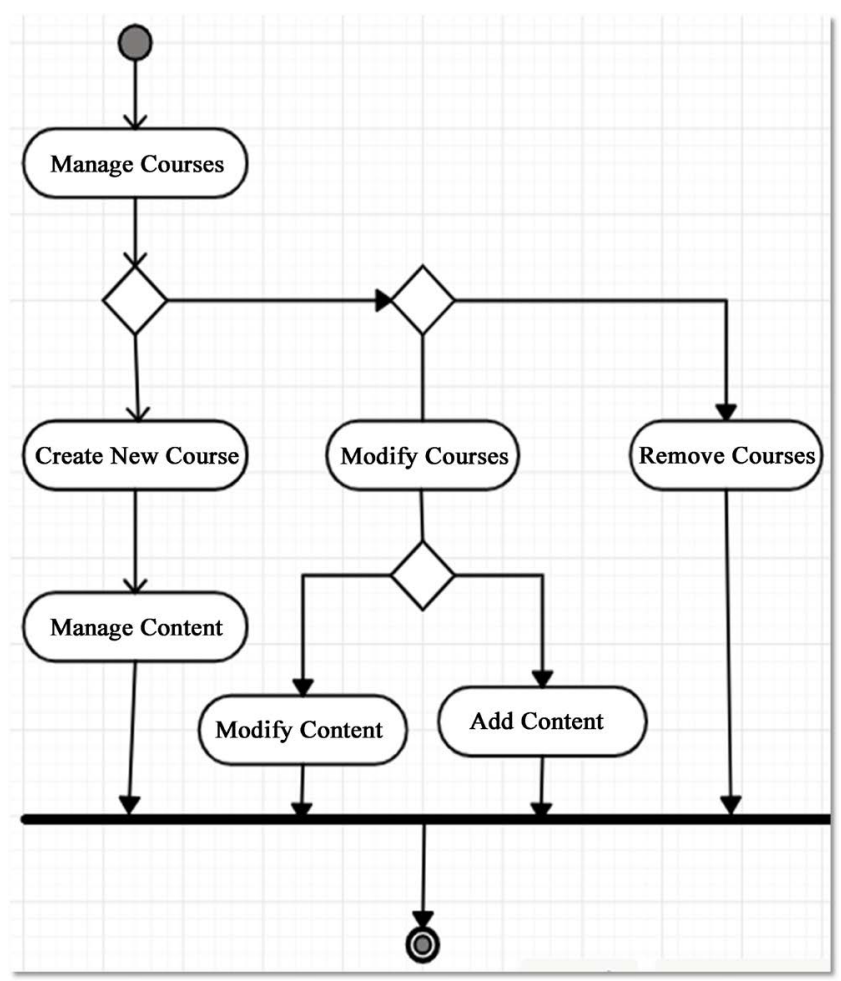

Figure 11. Sample activity diagram to manage courses. 


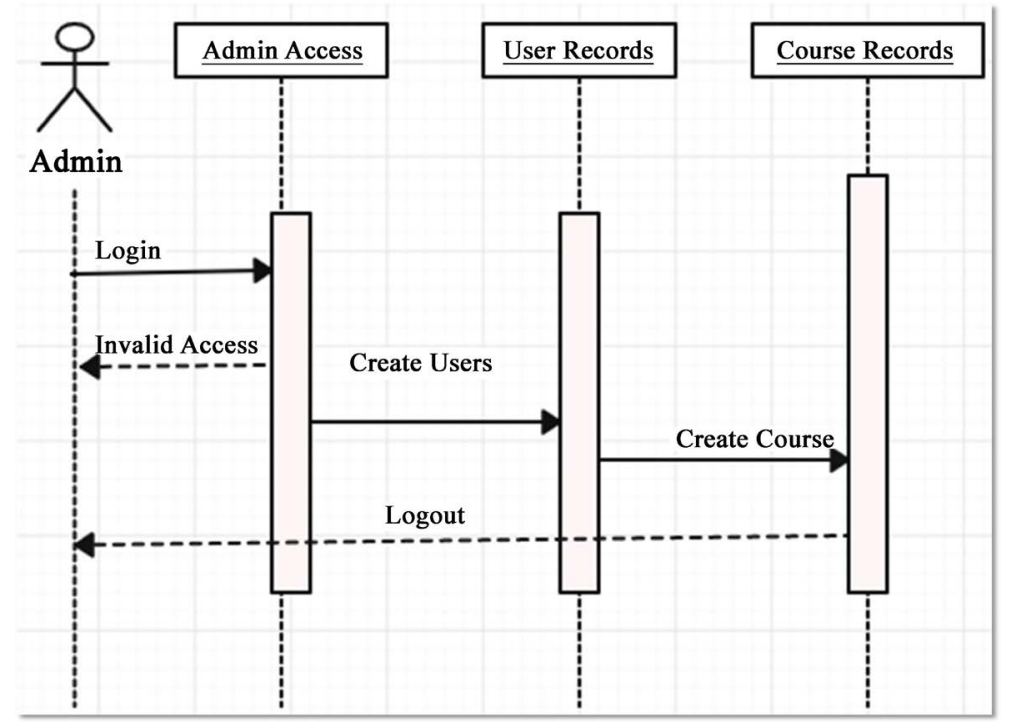

Figure 12. Sample sequence diagram to create course and user (Lecturers and Students).

\subsubsection{Prototype of the System}

The E-Learning system is designed to be easy to navigate, simple to look at, easy to access the available courses and its resources, user friendly and easy for students, Lecturers, administrator and other knowledge seekers.

The technologies that were used for development of the prototype are:

- HTML and CSS for designing the web interface of the prototype

- JavaScript used to write client side logic like validation and form submit and others. Also JQuery is used.

- PHP language used to write backend side or server side business logic of the prototype

- MySQL is used to store all the E-Learning data in the prototype

- Apache: this prototype is developed over apache server

- The site map of the proposed system is shown in Figure 13. A screenshot of the homepage and students' page are displayed in Figure 14 and Figure 15.

\subsubsection{Evaluation of the System}

To check the workability of the developed E-Learning web portal, the system test was performed through unit testing, integration and usability testing. The tests are intended to analyze the capability of the system based on the activities inside the system. The activities that was tested are create a user, manage courses, add activity and resources, conduct discussion through the system, manage online quizzes, manage upload and download assignment and materials. The prototype of the system was tested based on its functionality in Computing and Informatics College of Assosa University. The first two tests were done by the developers. In the unit testing scenario, the system has been tested in perspective of delivering academic resources (like course materials, assignments, quizzes and tutorials or online discussions) for students and gaining access to these academic resources. All these activities were performed by the lecturers, students and administrator. 
The lecturer distributed course materials, assignments, quizzes and discussion topics through the system. The students accessed the available resources from the system and the administrator manages courses, lecturers and students using the system.

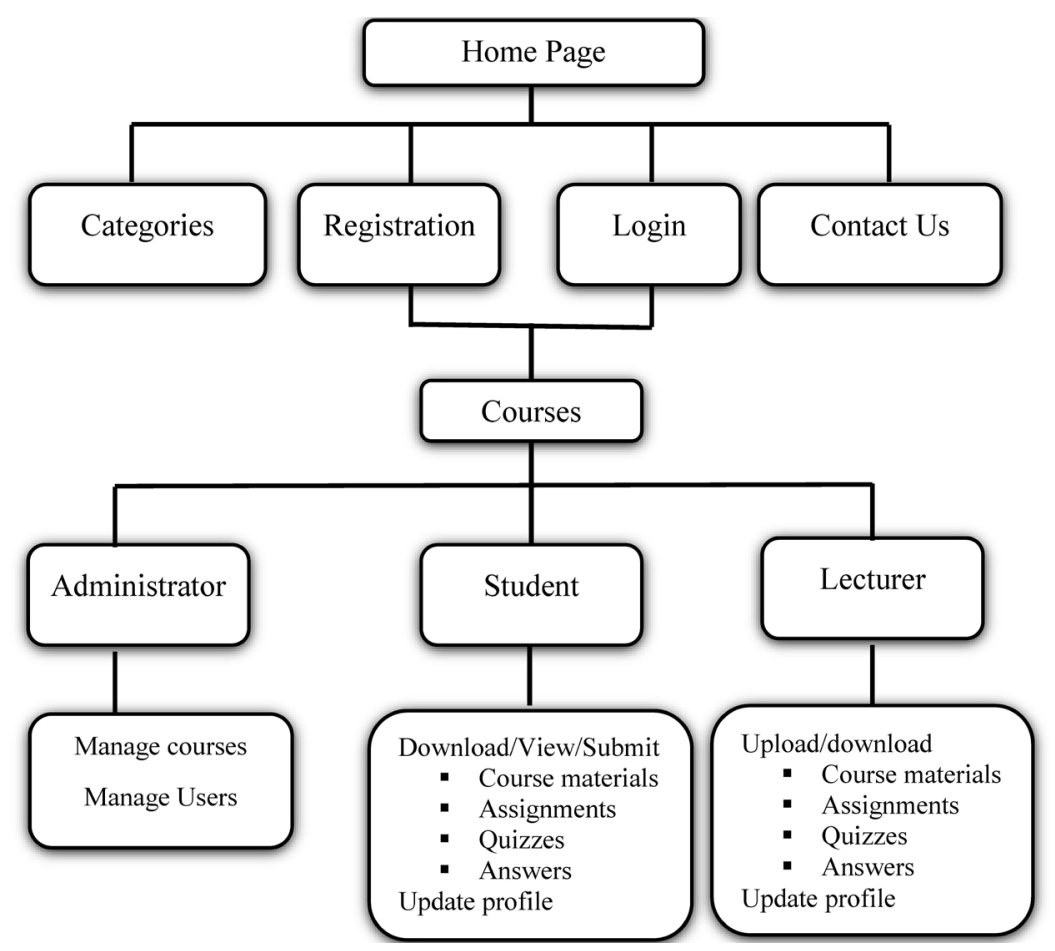

Figure 13. Site map for the proposed system.

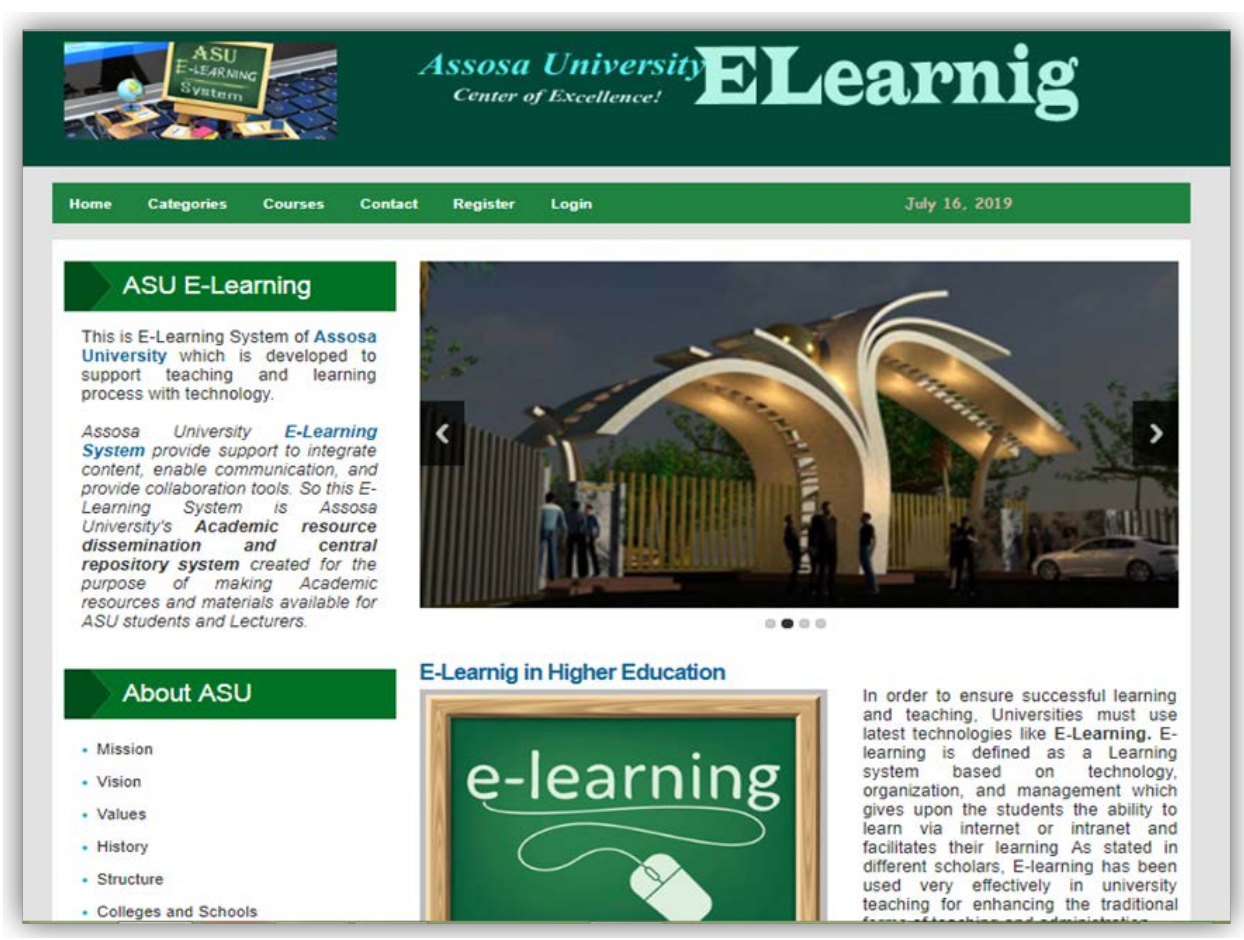

Figure 14. The home page ASU E-Learning prototype. 


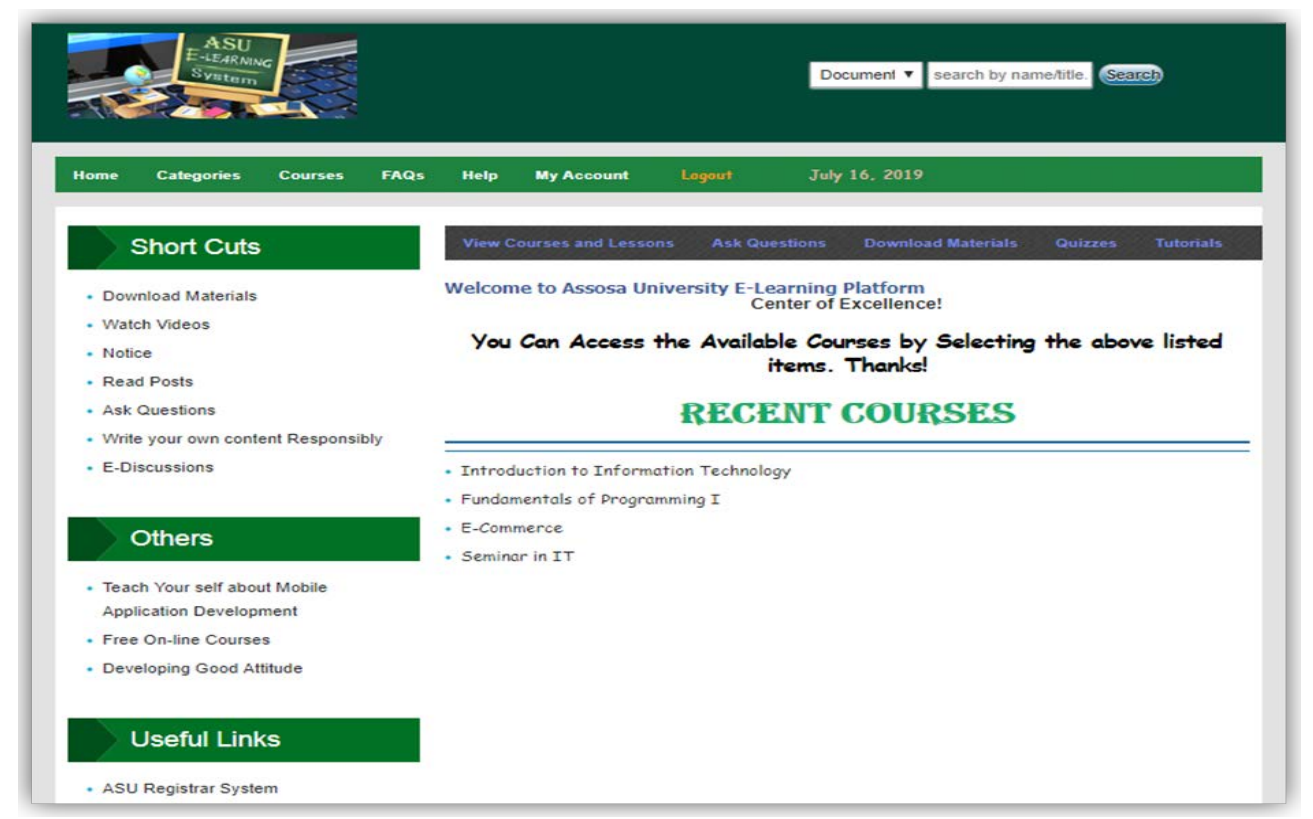

Figure 15. Students' page.

In the integration testing scenario, because the system is integration of different components, the test was based on unit interface, completeness of interface and by creating integrated test condition for all interfaces. The following integration test conditions were used

- Course resources, discussions and comments storing and retrieving test

- File processing test and search test were checked. Each interface are validated based on providing input and using output

- Course resources were sent from the web portal and stored in the local apache server and usage of the system were managed accordingly.

- Integration was done for course materials' (handouts, assignments, quizzes, etc.) delivering, accessing and management

The final test was usability testing, which was done using questionnaires. The test was done on the perspectives of students and lectures. This test was performed on how all students and lecturers use E-Learning web portal and attractiveness of the interface to use in Computing and Informatics College. They used the designed user interface and other features of the developed prototype. Finally, they suggest different additional issues that are to be included in the system. To test the proposed E-Learning system, each group of the users (students, lecturers and administrator) uses their own pages that are created for them. The potential user would assume if the system had been implemented and review it. The result analysis of the system uses Likert scale in rating. The ratings are 1 (poor), 2 (fair), 3 (good), 4 (very good) and 5 (excellent). Table 3 shows the usability result set together with the lead questions and number of rating.

As shown in the table above, the respondents have stated that the developed E-Learning system will improve quality of teaching and learning process in Assosa University. This is definitely the benefit of the implementation of the 
Table 3. Usabilit testing.

\begin{tabular}{|c|c|c|c|c|c|c|}
\hline No & Questionnaire & 1 & 2 & 3 & 4 & 5 \\
\hline 1 & Is E-Learning solutions make teaching and learning easier? & & & 8 & 16 & 8 \\
\hline 2 & Is the user interface of the prototype interactive? & & 4 & 8 & 12 & 8 \\
\hline 3 & Is all the necessary function found in the main menu & & 4 & 8 & 8 & 12 \\
\hline 4 & Is the course management is easy to use? & & 5 & 8 & 9 & 10 \\
\hline 5 & $\begin{array}{l}\text { Is the E-Learning system easy in writing and reading discusses } \\
\text { online? }\end{array}$ & & 4 & 8 & 8 & 12 \\
\hline 6 & $\begin{array}{l}\text { Is the developed E-Learning system easier for lecturers and } \\
\text { students to upload and download? }\end{array}$ & & 5 & 8 & 9 & 10 \\
\hline 7 & Is the implementation of E-Learning solution cost effective? & & 4 & 8 & 8 & 12 \\
\hline 8 & $\begin{array}{l}\text { Do you think that the time required to get the course materials } \\
\text { of learning will be improved? }\end{array}$ & & 8 & 12 & 6 & \\
\hline 9 & Do you think that this E-Learning system improve your ability? & & & 4 & 12 & 16 \\
\hline 10 & $\begin{array}{l}\text { Is the developed E-Learning system will effectively improve } \\
\text { teaching and learning quality in CCI, ASU? }\end{array}$ & & & 7 & 13 & 12 \\
\hline 11 & Is overall developed E-Learning system impressive? & & 9 & 8 & 15 & \\
\hline
\end{tabular}

E-Learning system where E-Learning will help students and lecturers in managing knowledge. This is the implementation of advanced technology too while many higher education institutions already use. E-Learning complies with their course management. The users also stated, they have good impression on developed E-Learning system and the function of E-discussion help the students to cooperate and get immediate assistant.

In addition to the above qualitative analysis regarding the capability of the developed E-Learning system, data were collected from interviews. Based on their qualitative feedback, it is found that students felt the developed E-Learning system is impressive. As they said, it will help the students to get resources from lecturer conveniently if the infrastructure is capable and sustainable. Also, the lecturers participated in this study to give their comments against the developed system and its impact on teaching and learning development. Both of the lecturers and students comment about the operation of the system that still is in focus. This is because the infrastructures need to be improved before fully implementing the system. They express their interest and clear positive comments towards the developing E-Learning system in College of Computing and Informatics at Assosa University

\section{Conclusion and Recommendation}

\subsection{Conclusion}

The use of E-Learning will make students interested in searching and upgrading their knowledge. However, as different studies and actual practices, different educational systems show that the experience of E-Learning to support teaching 
and learning includes different success and failures. Next to technological infrastructures, the lecturers and students greatly determine the success or failure of E-Learning implementation in one University. The results of this study have shown that, the possibility of implementing E-Learning in Assosa University is relatively high. Hence, E-Learning in Assosa University can be easily implementable by using the current man power, infrastructure and resources as well as by considering motives of students and lecturers in the University.

However, E-Learning in Assosa University has not been mainly implemented in the form of nonphysical presence of lecturers and students. This is because of the difficulties which are identified in this study. Some of these are: lack of technological skills, high cost of E-Learning incentives, lack of strategies, lack of computers, culture of the university teaching and learning process, student's fear of exposure in a new environment and others. In addition, some elements impose on Assosa University to use E-Learning like: technological advancement, enhancing teaching and learning, meeting students' expectations, improving students' technological skills, distributing course materials and others. So, it requires to create culture of online learning; more technologically advanced environment (like dedicated internet connection and availability of computer and other electronic device for each students) as well as it requires economic support from government and other organizations in terms of cost for designing and preparing E-Learning courses; moreover, it requires revision of educational model of the country. Therefore, the full implementation of E-Learning system in Assosa University must be based on the proposed framework that combines both traditional learning and E-Learning concepts.

In this regard, the implemented prototype showed that E-Learning is relevant and very useful for Assosa University. Among the opportunities that are gained from E-Learning are: it increases availability of academic resources; it is used as a repository of course materials for long life referencing and self-updating; it is used as additional communication channel for lecturers and students; it improves quality of education in some extent and the technological adoption of students and lecturers in the University.

Generally, the analysis of the collected data, the current situation of Assosa University and the country plus the present advancement of educational technologies indicated the possibility of implementation of E-Learning system in the University. We hope that the enablers, difficulties and features presented here will assist Assosa University in considering the significant aspects of E-Learning implementation.

\subsection{Recommendation}

This study was conducted to investigate the enablers, difficulties and features of E-Learning implementation in Assosa University. The findings from this study provide the following recommendations.

- Assosa University should implement E-Learning to guide and support teaching 
and learning with technology as well as to able to benefit or engage with E-Learning opportunities by considering some basic elements which includes:

- The infrastructure of the University must be strong and scalable; and provided with advanced technical skills.

- The University must find continuous and sustainable finance from government and international organizations that can provide funding and a platform to support teaching and learning with technology.

- The University must prepare E-Learning guidelines, polices, strategies and plans for future implementation. Also the management must support the use of educational technologies to improve quality of education and to connect with technologies.

- Providing capability building or digital literacy training about the diverse use of technologies and various levels of awareness, and truly interest, in the use of E-Learning in Assosa University is required. So, technological training offered to students and lecturers will ensure prerequisite skills to use E-Learning.

- In addition, result of this study is useful for other Ethiopian Universities which have not or newly deployed E-Learning system. So that, the proposed framework can be applied to other University educational systems in Ethiopia that are practically close to Assosa University like the $3^{\text {rd }}$ and $4^{\text {th }}$ generation Universities.

- Largely, to ensure E-Learning sustainability, Ethiopian science and higher education ministry must design well-structured E-Learning programs in all universities with the involvement of industries in the planning, development and delivery of E-courses. Also developing ICT policies or strategies to address curriculum issues is necessary.

\section{Acknowledgements}

We gratefully acknowledge Assosa University for the financial support. This is because it was not possible to conduct the study without the financial support. In addition, our great thanks go to all Computing and Informatics College and other staffs specially Information Technology department staffs in the University who provided insights and expertized that significantly assisted the study. Lastly, we would like to express our deepest appreciation to all those who provided us the possibility to complete the study.

\section{Conflicts of Interest}

The authors declare no conflicts of interest regarding the publication of this paper.

\section{References}

[1] Elletsom, H.A. (2015) The eLearning Africa Report. 
http://www.elearningafrica.com/report

[2] Stockley, D. (n.d.) E-Learning Definition and Explanation (Elearning, Online Training, Online Learning).

http://www.derekstockley.com.au/elearning-definition.html

[3] Himanshu Agarwal, G.P. (2013) Impact of E-Learning in Education. International Journal of Science and Research (IJSR), 2, 146-148.

[4] Zare, M.S.R. (2015) The Impacts of Multimedia Education on Learning and Retention in a Physiology Course. Media Electronic Learning Magazine.

[5] Bhuasiri, W.X. (2012) Critical Success Factors for e-Learning in Developing Countries: A Comparative Analysis between ICT Experts and Faculty. Computers \& Education, 58, 843-855. https://doi.org/10.1016/j.compedu.2011.10.010

[6] Clark, L. and Heaney, P. (2003) Author Online: Using Asynchronous Computer Conferencing to Support Literacy. British Journal of Educational Technology, 34, 57-66. https://doi.org/10.1111/1467-8535.00304

[7] Softwareadvice (n.d.) E-Learning Software. https://www.softwareadvice.com/lms/elearning-authoring-comparison/?utm sourc e=google-search\&utm medium=ppc\&utm term=elearning\%20systems\&utm matc htype $=\mathrm{p} \&$ network $=\mathrm{g} \& \mathrm{adpos}=1 \mathrm{t} 1$ \&utm campaign $=\mathrm{lms}$ desktop ph elearning\&ad $=349221826242 \&$ sitelink $=$ \&location $=9000411 \& g \mathrm{C}$

[8] Mohammad Behrouzian Nejad, E.B. (2014) Impact of E-Learning on Learning and Realizing Information Society. Research Journal of Applied Sciences, Engineering and Technology, 4, 5016-5020.

[9] Jones Paul, S.H. (2014) E-Learning Globalization: The Impact of e-Learning-What Difference Has It Made? Education and Training, 56. https://doi.org/10.1108/ET-11-2013-0128

[10] Sekiwu Denis, N.F. (2014) E-Learning for University Effectiveness in the Developing World. Global Journal of Human-Social Science, 14, 68-76.

[11] Esther, O.O. (2018) Learning Management System: A Tool for Effective Teaching Process. The International Journal of Science \& Technoledge, 6, 24-30.

[12] Shehabat, I.M. and Mahdi, S.A. (2009) E-Learning and Its Impact to the Educational System in the Arab World. International Conference on Information Management and Engineering, 220-225. https://doi.org/10.1109/ICIME.2009.74

[13] Taylor, S.J. (1998) Introduction to Qualitative Research Methods. 3rd Edition, John Wiley \& Sons Inc., Hoboken.

[14] Ali, S.U. (2018) A Conceptual Framework Highlighting e-Learning Implementation Barriers. Information Technology \& People, 31, 156-180.

https://doi.org/10.1108/ITP-10-2016-0246

[15] Mirzamohammadi, M.H. (2017) The Feasibility of E-Learning Implementation in an Iranian University. The Electronic Journal of e-Learning, 15, 423-432. http://www.ejel.org

[16] Gutierrez-Santuste, E.G.-A. (2016) Barriers in Computer-Mediated Communication: Typology and Evolution over Time. Journal of E-Learning and Knowledge Management, 12, 107-119.

[17] Leila Shahmoradi, V.C. (2018) The Challenges of E-Learning System: Higher Educational Institutions Perspective. Journal of Education Health Promotion, 7, 116.

[18] Muhammad, A.A. (2015) Resolving Ethical Dilemma in Technology Enhanced.

[19] Ross, S.M. (2010) Educational Technology Research Past and Present: Balancing 
Rigor and Relevance to Impact Learning. Contemporary Educational Technology, 1, 17-35. https://doi.org/10.30935/cedtech/5959

[20] Selwyn, N. (2011) Education and Technology: Key Issues and Debates. Continuum International Publishing Group, London. 